\title{
Multirotor UAV-Based Photogrammetric Mapping for Road Design
}

\author{
Muhammad Akmal Zulkipli and Khairul Nizam Tahar \\ Centre of Studies for Surveying Science and Geomatics, Faculty of Architecture, Planning, and Surveying, \\ Universiti Teknologi MARA, 40450 Shah Alam, Selangor Darul Ehsan, Malaysia \\ Correspondence should be addressed to Khairul Nizam Tahar; nizamtahar@gmail.com
}

Received 18 June 2018; Revised 6 August 2018; Accepted 13 September 2018; Published 1 October 2018

Guest Editor: Wei Liu

Copyright ( 2018 Muhammad Akmal Zulkipli and Khairul Nizam Tahar. This is an open access article distributed under the Creative Commons Attribution License, which permits unrestricted use, distribution, and reproduction in any medium, provided the original work is properly cited.

\begin{abstract}
Unmanned Aerial Vehicles (UAVs) can be used for close range mapping. In engineering survey works, the conventional survey involves huge cost, labour, and time. Low-cost UAVs are very practical in providing reliable information for many applications such as road design. UAV s can provide the output that meets the accuracy of engineering surveys and policies, especially for small-scale mapping. UAVs are also a competitive technology which is stable and rapidly developing, same as other surveying technologies. This study investigates the performance of multirotor UAV for road design. This study involves four phases which consist of preliminary study, data collection, data processing, and analysis. This study focuses on the UAV as a tool to capture data of the ground from a certain altitude. The analysis includes UAV flight planning, image acquisition, and accuracy assessment of road design. It can be concluded that UAVs can be used to provide data for road design with reliable accuracy.
\end{abstract}

\section{Introduction}

Developed countries are constantly faced with high maintenance cost of aging transportation highways. The growth of the motor vehicle industry and accompanying economic growth has generated a demand for safer, better performing, less congested highways [1]. The growth of commerce, educational institutions, housing, and defense has largely drawn from government budgets in the past, making the financing of public highways a challenge. The multipurpose characteristics of highways, economic environment, and the advances in highway pricing technology are constantly changing. Therefore, the approaches to highway financing, management, and maintenance are constantly changing as well. Management of safety is a systematic process that strives to reduce the occurrence and severity of traffic accidents. The man/machine interaction with road traffic systems is unstable and poses a challenge to highway safety management [2]. High accuracy of topographical information and features information are very important in good road alignment design [3]. There are many previous methods used to capture topography information such as manned satellite imagery, radar, LiDAR, and land survey. The Ground Sampling Distance (GSD) is the most important characteristic to be considered during road design. The other information such as elevation and positioning also influences the road design.

Previously, topography information especially in road design was obtained from land survey using total station. The land survey method required a lot of time to complete the survey especially for large area. Therefore, this method also increased the cost of the project and labour used to complete the project. The land survey method totally relies on human resource in order to carry out road design. Therefore, the road design is prone to the systematic error done by human. The undulated area is a challenge for land survey method because it requires the human to climb up and down and access the challenging site on their own. The other factor is weather conditions and land ownership issue during conducting the land survey. The long road alignment might cause a lot of errors and it might have problem to merge the data at the end [4]. The other method used to capture topography information is Light Detection and Ranging (LiDAR). This method offers the accurate topographic data 
for road design application. LiDAR method can cover the large area in a minutes and could provide the accurate data. LiDAR is also an active sensor which is capable of capturing data the day or night. However, this method is very expensive which can affect the total project cost. Satellite imagery also can be used to obtain topographic information for road design application. The satellite imageries were captured from thousand kilometres from the earth surface [5]. This method could provide the location and classification of topographic information. This method also has its own problem due to the revisit time of the satellite at the same location, weather condition which refer to cloudy condition, and resolution of the satellite images.

The key for increasing the safety of highway systems is to design, build, and maintain them to be far more tolerant of the average range of this man or machine interaction with highways. Technological advancements in highway engineering have improved the design, construction, and maintenance methods used over the years. These advancements have allowed for newer highway safety innovations. By ensuring that all situations and opportunities are identified, considered, and implemented as appropriate, they can be evaluated in every phase of highway planning, design, construction, maintenance, and operation to increase the safety of our highway systems.

The new technology such as UAV photogrammetry opens numerous applications in the close range domain, combining aerial and terrestrial photogrammetry but also introduces low-cost alternatives to the conventional manned aerial photogrammetry [6-9]. UAV systems also offer various applications other than mapping such as surveillance, archeological, geohazard studies, monitoring, and fire disaster [1022]. The UAV system is equipped with various intelligent sensors such as barometer, Inertial Navigation System (INS), Global Positioning System (GPS), flight control, navigation control, sonar, and infrared and Electronic Speed Controller (ESC) [23-27]. There are many kinds of UAVs available in the market which are affordable. UAV photogrammetry describes photogrammetric measurement platforms which operate as either remotely controlled, semiautonomously, or autonomously. The definition covers balloons, kites, gliders, airships, rotary, and fixed wing UAVs with the capability for photogrammetric data acquisition in manual, semiautomated, and automated flight modes [28]. Model helicopters are able to operate closer to the object and are highly flexible in navigation compared to fixed wing UAVs. Microdrones are more stable against environmental conditions such as wind. The developments of model helicopters and comparable autonomous vehicles are primarily driven by the artificial intelligence. Nowadays, close range areas can be mapped by combining aerial and terrestrial photogrammetry using UAV technologies and also as an alternative way for large area mapping [29]. Low cost UAVs are used in mapping projects with low budgets. However, in the previous years, low-cost UAVs have reached a level of practical reliability and professionalism which allow the use of these systems such as mapping platforms. In study, the multirotor UAV is used to capture the topographic information for road design application.

\section{Methodology}

This study involves four phases which include preliminary study and planning, data collection, data processing, results, and analysis. The methodology plays an important role in implementing this study accordingly. The first phase is on the preliminary study and the planning of the work which are crucial parts of the study that require a lot of reading and planning. The first phase also includes reconnaissance, calibration of the equipment, and measurement of data. The next phase is on data collection using UAV images and getting the detailed plans from the unit facilities of UiTM Puncak Alam. Then, both sets of data are processed in the laboratory for the third phase of this study which is data processing. The UAV images are processed using the UAV Agisoft PhotoScan software which can generate the $\mathrm{X}, \mathrm{Y}$, and $\mathrm{Z}$ coordinates of the proposed road. This phase also includes the construction of road mapping of the area of interest. After the data processing is completed, the results are analysed. The flowchart of the research methodology is shown in Figure 1.

Reconnaissance survey is a general study of an area of interest that might be used for a road or airfield. The reconnaissance survey report should summarise all the collected information, including a description of the site, a conclusion on the economy of its use, and, wherever possible, maps. For UAV surveys, the important thing is the area of coverage of the site. Furthermore, the reconnaissance must include geographical features for the decision-making of minimum flying height, direction of flight path, and type of UAV used. Other than that, this survey also needs to consider the wind direction to make sure that it is carried out smoothly and also for the direction of the flying path to obtain better image capture. Figure 2 shows the location of study. Camera calibration is carried out before acquiring the digital aerial images or aerial photographs for the purpose of recovering all camera parameters for digital image processing. This study used a $4 \mathrm{~K}$ camera with $4000 \times 3000$ resolution and the process of camera calibration also gives a result of focal length, principal points, radial lens distortion, and tangential lens distortions. These camera parameters need to be included during the interior orientation step in digital image processing

The UAV used in this study is the Quad-Rotors, Phantom 3 Professional. The UAV weight (including battery and propellers) is about $1280 \mathrm{~g}$ and the diagonal size (excluding propellers) is $350 \mathrm{~mm}$. Its maximum speed can achieve 16 $\mathrm{m} / \mathrm{s}$ (ATTI mode, no wind) and has a GPS Mode that uses GLONASS satellite. The UAV maximum flight time is approximately about 23 minutes. A single person can operate this UAV to collect the image data. The hardware uses IOS Ipad to control the flight planning and a computer for processing. The detailed plan is acquired from the unit facilities in the DWG file in AutoCAD and it can be georeferenced using the ArcGIS software. After that, the acquired UAV images were processed using the Agisoft PhotoScan software. Next, the outputs are transferred to the AutoCAD and the ArcGIS software to analyse the outputs.

2.1. Data Acquisition and Flight Planning. Flight planning involves the control of dimension of the study area, number 


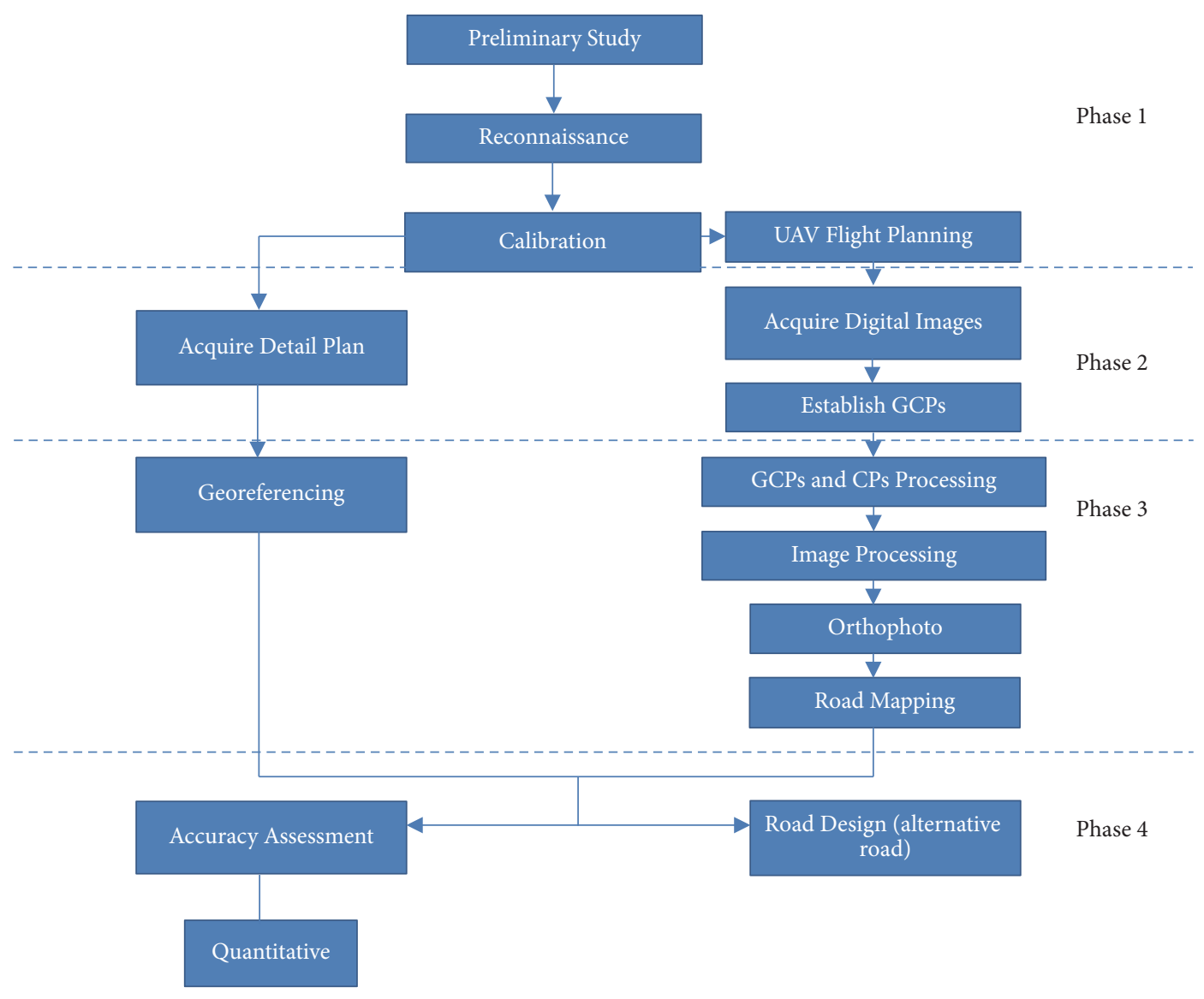

Figure 1: Research methodology.

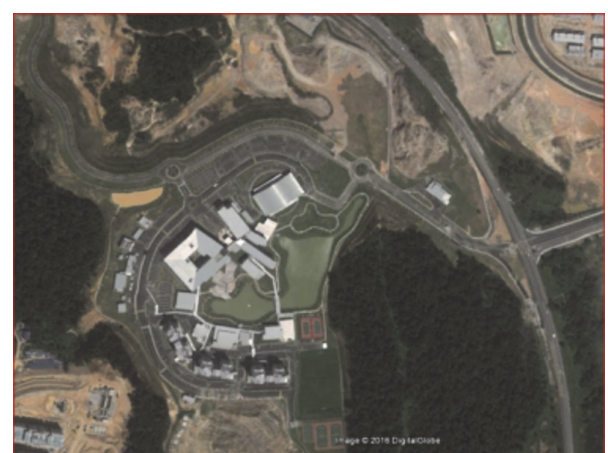

FIGURE 2: Location of study area.

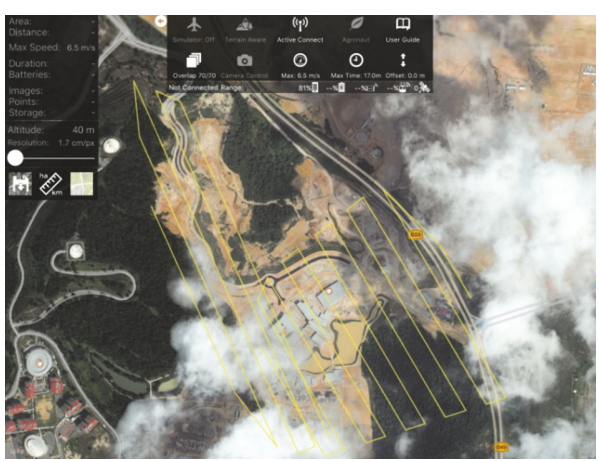

FIGURE 3: Flight planning for acquisition of data. of strips required, pixel size, photo scale flying height, and percentage of the end lap and side lap. The Map Pilot used is a friendly software for the drone, module Waypoint Editor, and it is able to design flight planning. There are about 122 number of images with $148 \mathrm{~m}$ flying height created in the flight planning. In general, the aerial photographs should be overlapped at least $80 \%$ and the side for at least $60 \%$. This requirement needs to be fulfilled to make sure that quality photogrammetry results could be obtained. The customised parameters such as spatial resolution, altitude, endlap, sidelap, and wind direction are as shown in Figure 3. After parameters setting of the flight planning is completed in the Map Pilot, the flight planning is uploaded to the UAV. After uploading, the start button is pressed to begin the image acquisition. Once it started, the UAV gave information of the current altitude of the mission. After the UAV entered the survey area, images are automatically captured every 2.5 seconds and identical speed is used to ensure accurate data. Once the mapping is completed, the UAV returned to the takeoff location and landed automatically. 
TABLE 1: Coordinates of road design.

\begin{tabular}{|c|c|c|c|c|c|c|}
\hline \multirow{2}{*}{ CPs } & \multicolumn{3}{|c|}{ Conventional Road Design } & \multicolumn{3}{|c|}{ UAV Images road Design } \\
\hline & $\mathbf{X}(\mathbf{m})$ & $\mathrm{Y}(\mathbf{m})$ & $\mathrm{Z}(\mathbf{m})$ & $\mathbf{X}(\mathbf{m})$ & $\mathrm{Y}(\mathbf{m})$ & $\mathrm{Z}(\mathbf{m})$ \\
\hline $\mathrm{CP1}$ & -26926.806 & 3109.908 & 42.124 & -26926.435 & 3110.456 & 41.431 \\
\hline $\mathrm{CP2}$ & -26847.403 & 3128.347 & 44.154 & -26847.554 & 3128.184 & 44.310 \\
\hline CP3 & -26715.708 & 3158.090 & 39.246 & -26716.024 & 3157.619 & 38.570 \\
\hline $\mathrm{CP} 4$ & -26813.002 & 3178.296 & 41.423 & -26813.127 & 3178.034 & 41.133 \\
\hline CP5 & -27024.207 & 3186.877 & 43.806 & -27024.254 & 3186.939 & 44.205 \\
\hline CP6 & -26967.798 & 3240.365 & 43.403 & -26967.768 & 3240.422 & 43.903 \\
\hline CP7 & -27064.443 & 3216.702 & 43.206 & -27064.472 & 3216.801 & 43.322 \\
\hline CP8 & -27167.600 & 3078.530 & 44.500 & -27167.648 & 3078.670 & 44.406 \\
\hline CP9 & -27188.670 & 2957.179 & 44.720 & -27188.601 & 2957.334 & 45.069 \\
\hline CP10 & -27182.072 & 2969.390 & 44.407 & -27181.878 & 2969.580 & 45.146 \\
\hline CP11 & -27078.698 & 2825.722 & 48.370 & -27078.685 & 2825.727 & 48.610 \\
\hline $\mathrm{CP12}$ & -26879.317 & 2724.228 & 48.912 & -26879.289 & 2724.209 & 48.114 \\
\hline CP13 & -26860.444 & 2769.504 & 49.188 & -26860.493 & 2769.433 & 48.635 \\
\hline CP14 & -26851.342 & 2876.084 & 45.039 & -26851.430 & 2875.994 & 44.772 \\
\hline
\end{tabular}

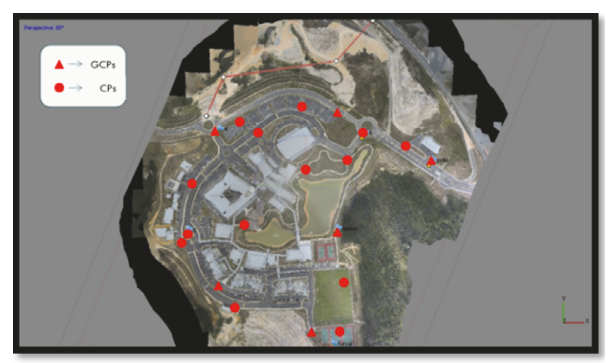

Figure 4: Location of GCPs and CPs.

2.2. Preprocessing and Processing. The ground control points (GCPs) and check points (CPs) are collected using GPS observation through the rapid static technique. This technique can determine the position information which includes Northing, Easting, and Elevation (X, Y, and Z) through postprocessing by using the GNSS Solution software. This software can convert the raw data to a Rinex file, where it can be used in any GPS processing software for adjustments. The rapid static technique only takes 5 to 20 minutes for observation. In this study, there are six GCPs established for absolute orientation and fourteen CPs. For a better view, Figure 4 shows all the locations of the GCPs and CPs.

After data acquisition has been completed using the multirotor UAV, all acquired raw images data and GCPs are processed using the Agisoft PhotoScan software. The results are presented in the form of a digital map or hardcopy. The Agisoft PhotoScan software requires camera information such as pixel size, focal length, radial lens distortion, and tangential distortion to carry out the interior orientation. A total of six GCPs have been established during absolute orientation. After adding the raw images data in the Agisoft PhotoScan software, the process will start with aligning the photo input in a high accuracy setting and using the Reference for Pair Preselection. The key and tie point limit are 40,000 and 20,000. After aligning the photos, a reference to establish the GCP on the UAV images is selected by importing the coordinates in the (txt) file. The coordinate is illustrated by point features in the software, where it needs to move the point to the exact location of the GCP. The process will produce Orthophoto and a map.

2.3. Data Analysis and Assessment. The objective of this study is to assess the accuracy of road mapping from the UAV product. There are two assessments describing the point and visual analysis. For quantitative accuracy, the error difference between the coordinates of check points by GPS (rapid static technique) and UAV processed images data is assessed using RMSE. After the accuracy assessment has been conducted, an alternative road can be designed using the UAV data and ground survey mapping of the study area. The designed road is focused on increasing the efficiency of road flow. The optimal road alignment is determined based on topographic map of the area and mapping the existing road network. There are two types of alignments which are vertical and horizontal alignment. The horizontal and vertical alignments based on topographic features from the UAV data are determined.

\section{Results and Analysis}

The analysis of the accuracy of the road mapping, production of the road map and all the results will be analysed in this chapter, including the evaluation of UAV images for road design or alternative road. All calculations are made for the RMSE point accuracy assessments and the road design. The accuracy is analysed based on computation of the RMSE between the coordinates of 3D stereo model and the check points. The locations of the check points are shown in Figure 4 with 14 samples (Table 1). It shows the comparisons between CPs using GPS and the 3D coordinates of the stereo model in Agisoft Photoscan software.

It can be seen that the accuracy could be achieved using the UAV system. The smaller the value of the RMSE 


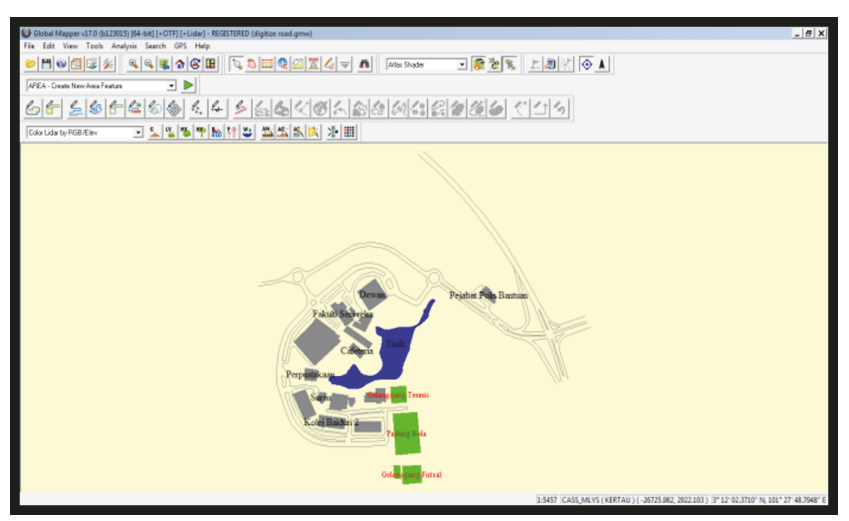

FIGURE 5: Digitized features from UAV images.

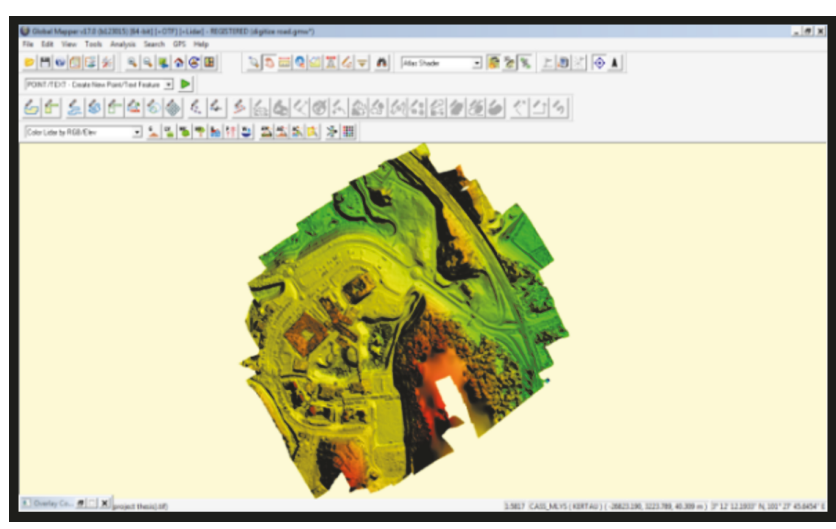

FIGURE 6: Digital surface models of UAV images data.

calculated, the higher the accuracy. Hence, the accuracy of the orthophoto can be calculated by the RMSE value. The latitude, longitude, and elevation (X, Y, and $\mathrm{Z}$ ) are processed using the GNSS Solution software where the raw data collected from the site are converted to (Rinex) file to be used in any GPS processing software for adjustments. After processing the raw data of the UAV images in the Agisoft Photoscan software, the outcome of orthomosaic in a (tif) file will be imported to the Global Mapper software in order to carry out the digitisation of the features as shown in Figure 5. The analyses are carried out based on road features and the elevation produced by the Digital Surface Model (DSM) (Figure 6). The digitised features are displayed in ArcGIS to visualise the difference from the AutoCAD drawing.

After both road designs are completed, both UAV images and conventional road design are compared with the coordinate of chainage in every 30 meter intervals. In the CDS software, parameters of the road are needed to design the road curve such as bearing in, bearing out, and the optimum radius for the road curve. Two road curves have been designed with the radius of 50 and 60 meters for the first and second curve. After clicking the position of the Intersection Point and keying in the value of radius, bearing in and bearing out the software will calculate the other parameters values which are available for the designed road curve such as arc, chord, and tangent length. Figure 7 shows the finished road design

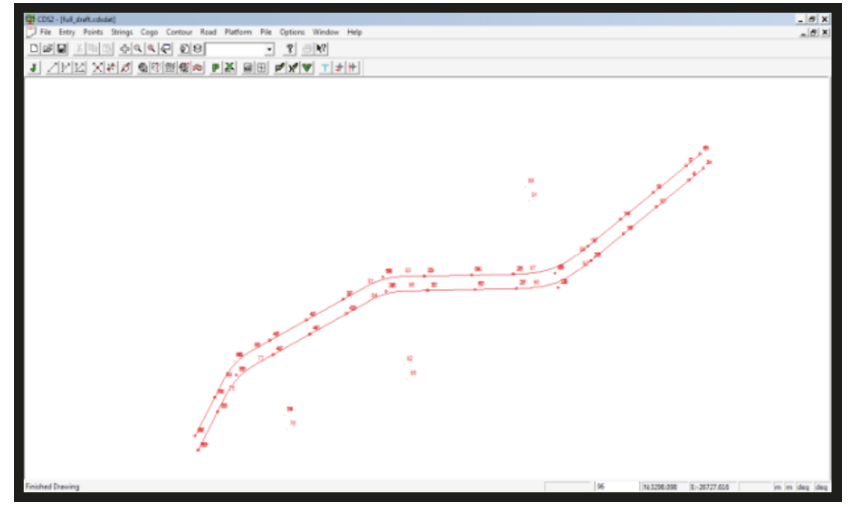

FIGURE 7: Complete road designs for UAV Images and Conventional Survey.

with 50 and $60 \mathrm{~m}$ radius. This radius follows the public work department standards for Exclusive Motorcycle Lane, EML.

\section{Discussions}

After producing the adjustment coordinates, the WGS84 coordinate system is converted to a local coordinate system from angular units to meters. The coordinate system that is chosen is Cassini Malaysia, Selangor, by using Kertau as a datum. The reason that the coordinate system is converted to Cassini Malaysia is because it is easy to analyse the meter units than the angular degree minutes and seconds, where it can check the miss-closure (meter) of the data. The RMSE for $\mathrm{x}, \mathrm{y}$, and $\mathrm{z}$ coordinates are \pm 0.155 metres, \pm 0.228 metres, and \pm 0.479 metres, respectively (Table 2 ).

In the Global Mapper software, digitising of features are carried out using orthophoto image and then exported to ArcGIS in order to produce a map. The analysis only focused on road features and it could be displayed in ArcGIS to visualise the differences between UAV road mapping and conventional road mapping. The AutoCAD drawings are obtained from the unit facilities of UiTM Puncak Alam. Figure 8 shows the slight difference between two methods of producing the map; the road with the pink outline is drawn using the AutoCAD software which is obtained from conventional ground measurement while the grey outline is digitised from the UAV's orthophoto in the Global Mapper software.

\section{Conclusions and Recommendations}

Road mapping is produced from the UAV images using the Agisoft Photoscan software to create an orthophoto image. All the images went through the scaling and level process which also referred to the orientations such as interior, relative, and exterior orientation. It is demonstrated that the UAV together with the digital camera are capable of acquiring aerial photograph successfully for large scale mapping in a short amount of time. This study shows that UAV is also capable of producing road mapping at the selected study area. All of the results are analysed using the Root Mean 
TABLE 2: Analysis on disparity between conventional and UAV coordinates.

\begin{tabular}{|c|c|c|c|c|c|c|}
\hline CPs & $\mathrm{X}(\mathrm{m})$ & $\mathrm{Y}(\mathrm{m})$ & $\mathrm{Z}(\mathrm{m})$ & $\mathrm{X}^{2}(\mathrm{~m})$ & $\mathrm{Y}^{2}(\mathrm{~m})$ & $\mathrm{Z}^{2}(\mathrm{~m})$ \\
\hline CP1 & -0.371 & -0.548 & -0.693 & 0.138 & 0.300 & 0.480 \\
\hline $\mathrm{CP} 2$ & 0.151 & 0.163 & -0.156 & 0.023 & 0.027 & 0.024 \\
\hline $\mathrm{CP} 3$ & 0.316 & 0.471 & 0.676 & 0.100 & 0.222 & 0.457 \\
\hline CP4 & 0.125 & 0.262 & 0.290 & 0.016 & 0.069 & 0.084 \\
\hline CP5 & 0.047 & -0.062 & -0.399 & 0.002 & 0.004 & 0.159 \\
\hline $\mathrm{CP6}$ & -0.030 & -0.057 & -0.500 & 0.001 & 0.003 & 0.250 \\
\hline CP7 & 0.029 & -0.099 & -0.116 & 0.001 & 0.010 & 0.013 \\
\hline CP8 & 0.048 & -0.140 & 0.094 & 0.002 & 0.020 & 0.009 \\
\hline CP9 & -0.069 & -0.155 & -0.349 & 0.005 & 0.024 & 0.122 \\
\hline CP10 & -0.194 & -0.190 & -0.739 & 0.038 & 0.036 & 0.546 \\
\hline CP11 & -0.013 & -0.005 & -0.240 & 0.000 & 0.000 & 0.058 \\
\hline CP12 & -0.028 & 0.019 & 0.798 & 0.001 & 0.000 & 0.637 \\
\hline CP13 & 0.049 & 0.071 & 0.553 & 0.002 & 0.005 & 0.306 \\
\hline CP14 & 0.088 & 0.090 & 0.267 & 0.008 & 0.008 & 0.071 \\
\hline RMSE (m) & & & & 0.155 & 0.228 & 0.479 \\
\hline
\end{tabular}

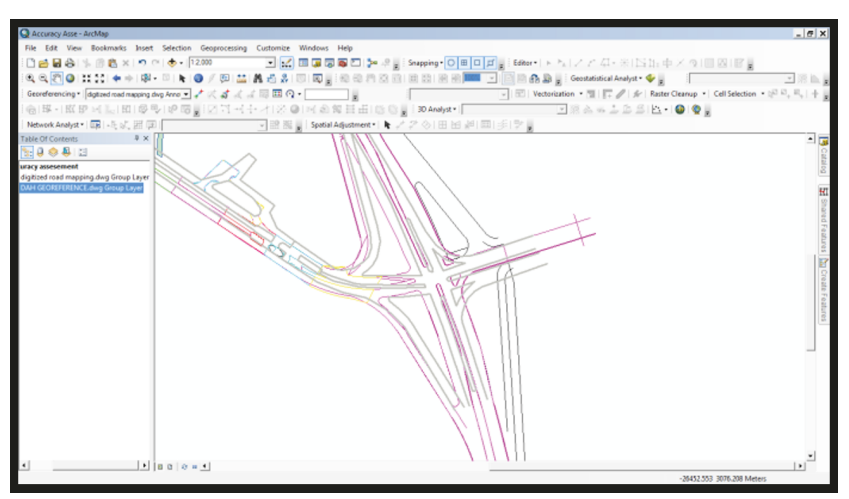

Figure 8: Visual Accuracy Assessments of Both Road Designs.

Square Error (RMSE). RMSE can assess the accuracy of the UAV images using the check points that have been measured on the ground for data validation analysis. The designed road in this study is for proposing an alternative road to increase the efficiency of road traffic flow. The Digital Terrain Model (DTM) data from the UAV images processed is used to evaluate the geographic features where it must follow the design policy parameters in order to help control the design of the road. The safety of the users must also be calculated by selecting the super elevation of the proposed road. Therefore, the alternative road can be designed using the parameters for road design provided by public work department standards. In the future, the accuracy of the orthophoto can be improved and enhanced by increasing the number of GCPs and CPs during data collection in the field using the GPS technique. It can also minimise the RMSE in data processing. The use of DTM (digital terrain model) for road design to check the accuracy of the road designed and to improve the validation of using UAV for road design construction. Different types of UAV should be used to improve the flexibility of the survey works; for example, a fixed wing UAV can cover a large area to get more details for the topographical map to design a road. Different methods of camera calibration could be applied to optimise the quality of the UAV image processing. MyRTKnet data should be used as a base for better control of the coordinate GCP to apply on the UAV images for processing. Different flying heights should be applied for UAV to conduct better results for road design.

\section{Data Availability}

The data used to support the findings of this study are available from the corresponding author upon request.

\section{Conflicts of Interest}

The authors declare that they have no conflicts of interest.

\section{Acknowledgments}

Faculty of Architecture, Planning, and Surveying Universiti Teknologi MARA (UiTM), Research Management Institute (RMi), and Ministry of Higher Education (MOHE) are greatly acknowledged for providing the fund BESTARI 600IRMI/MyRA 5/3/BESTARI (001/2017) to enable this research to be carried out. The authors would also like to thank the people who were directly or indirectly involved in this research.

\section{References}

[1] Z. Jaal and J. Abdullah, "User's Preferences of Highway Landscapes in Malaysia: A Review and Analysis of the Literature," Procedia - Social and Behavioral Sciences, vol. 36, pp. 265-272, 2012.

[2] S. Martínez, J. Ortiz, and M. L. Gil, "Geometric documentation of historical pavements using automated digital photogrammetry and high-density reconstruction algorithms," Journal of Archaeological Science, vol. 53, pp. 1-11, 2015. 
[3] M. M. S. Albattah, "Optimum Highway Design and Site Location Using Spatial Geoinformatics Engineering," Journal of Remote Sensing \& GIS, vol. 5, no. 1, p. 10, 2016.

[4] P. Kettunen, C. Koski, and J. Oksanen, "A design of contour generation for topographic maps with adaptive DEM smoothing," International Journal of Cartography, vol. 3, no. 1, pp. 19-30, 2017.

[5] F. van Coillie, K. Delaplace, D. Gabriels et al., "Monotemporal assessment of the population structure of Acacia tortilis (Forssk.) Hayne ssp. raddiana (Savi) Brenan in Bou Hedma National Park, Tunisia: A terrestrial and remote sensing approach," Journal of Arid Environments, vol. 129, pp. 80-92, 2016.

[6] H. Eisenbeiss, UAV Photogrammetry, DISS. ETH NO. 18515, 1237, 2009.

[7] Y. Fujii, E. Fodde, K. Watanabe, and K. Murakami, "Digital photogrammetry for the documentation of structural damage in earthen archaeological sites: the case of Ajina Tepa, Tajikistan," Engineering Geology, vol. 105, no. 1-2, pp. 124-133, 2009.

[8] Z. Lin, "UAV aiborne low altitude photogrammetry system," Science of Surveying and Mapping, vol. 36, no. 1, p. 5, 2011.

[9] M. A. Núñez, F. Buill, and M. Edo, "3D model of the Can Sadurní cave," Journal of Archaeological Science, vol. 40, no. 12, pp. 4420-4428, 2013.

[10] H. Bendea, F. Chiabrando, F. Tonolo, and D. Marenchino, "Mapping of archaeological areas using a low-cost UAV the Augusta Bagiennorum Test," XXI International CIPA Symposium, pp. 18, 2007.

[11] I. Colomina and P. Molina, "Unmanned aerial systems for photogrammetry and remote sensing: a review," ISPRS Journal of Photogrammetry and Remote Sensing, vol. 92, pp. 79-97, 2014.

[12] G. J. Grenzdörffer, M. Guretzki, and I. Friedlander, "Photogrammetric image acquisition and image analysis of oblique imagery," The Photogrammetric Record, vol. 23, no. 124, pp. 372386, 2008.

[13] R. N. Jiang and D. V. Jauregui, "Development of a digital closerange photogrammetric bridge deflection measurement system," Measurement, vol. 43, no. 10, pp. 1431-1438, 2010.

[14] T. Luhmann, "Close range photogrammetry for industrial applications," ISPRS Journal of Photogrammetry and Remote Sensing, vol. 65, no. 6, pp. 558-569, 2010.

[15] K. Konolige and M. Agrawal, "FrameSLAM: From bundle adjustment to real-time visual mapping," IEEE Transactions on Robotics, vol. 24, no. 5, pp. 1066-1077, 2008.

[16] S. G. Kontogiannis and J. A. Ekaterinaris, "Design, performance evaluation and optimization of a UAV," Aerospace Science and Technology, vol. 29, no. 1, pp. 339-350, 2013.

[17] M. Röder, H. Latifi, S. Hill et al., "Application of optical unmanned aerial vehicle-based imagery for the inventory of natural regeneration and standing deadwood in post-disturbed spruce forests," International Journal of Remote Sensing, pp. 122, 2018.

[18] L. Sahar, S. Muthukumar, and S. P. French, "Using aerial imagery and gis in automated building footprint extraction and shape recognition for earthquake risk assessment of urban inventories," IEEE Transactions on Geoscience and Remote Sensing, vol. 48, no. 9, pp. 3511-3520, 2010.

[19] S. Pal Singh, K. Jain, and V. Mandla, "Virtual 3D Campus Modeling by Using Close Range Photogrammetry," American Journal of Civil Engineering and Architecture, vol. 1, no. 6, pp. 200205, 2013.
[20] K. N. Tahar and A. Ahmad, "Production of Orthophoto and Volume Determination Using Low-Cost Digital Cameras," Pertanika Journal of Science and Technology, vol. 21, no. 2, pp. 387396, 2011.

[21] P. Xiaodong and L. Zongjian, "Unmanned airship low altitude system for aerial photogrammetry," Science of Surveying and Mapping, vol. 34, no. 4, pp. 33-35, 2009.

[22] X. Du, X. Jin, X. Zhang, J. Shen, and X. Hou, "Geometry features measurement of traffic accident for reconstruction based on close-range photogrammetry," Advances in Engineering Software, vol. 40, no. 7, pp. 497-505, 2009.

[23] J. Chahl, "Three biomimetic flight control sensors," International Journal of Intelligent Unmanned Systems, vol. 2, no. 1, pp. 27-39, 2014.

[24] H. Chao, Y. Cao, and Y. Chen, "Autopilots for small unmanned aerial vehicles: A survey," International Journal of Control, Automation, and Systems, vol. 8, no. 1, pp. 36-44, 2010.

[25] F. Delgado, J. Carvalho, T. Coelho, and A. Dos Santos, "An Optical Fiber Sensor and Its Application in UAVs for Current Measurements," Sensors, vol. 16, no. 11, p. 1800, 2016.

[26] S. Jabari, F. Fathollahi, A. Roshan, and Y. Zhang, "Improving UAV imaging quality by optical sensor fusion: an initial study," International Journal of Remote Sensing, vol. 38, no. 17, pp. 49314953, 2017.

[27] A. B. Junaid, Y. Lee, and Y. Kim, "Design and implementation of autonomous wireless charging station for rotary-wing UAVs," Aerospace Science and Technology, vol. 54, pp. 253-266, 2016.

[28] H. Eisenbeiss, Photogrammetric Week '11, F. Dieter, Ed., 2011, Wichmann/VDE Verlag, Belin \& Offenbach.

[29] K. N. Tahar and A. Ahmad, "A simulation study on the capabilities of rotor wing unmanned aerial vehicle in aerial terrain mapping," International Journal of Physical Sciences, vol. 7, no. 8, 2012. 

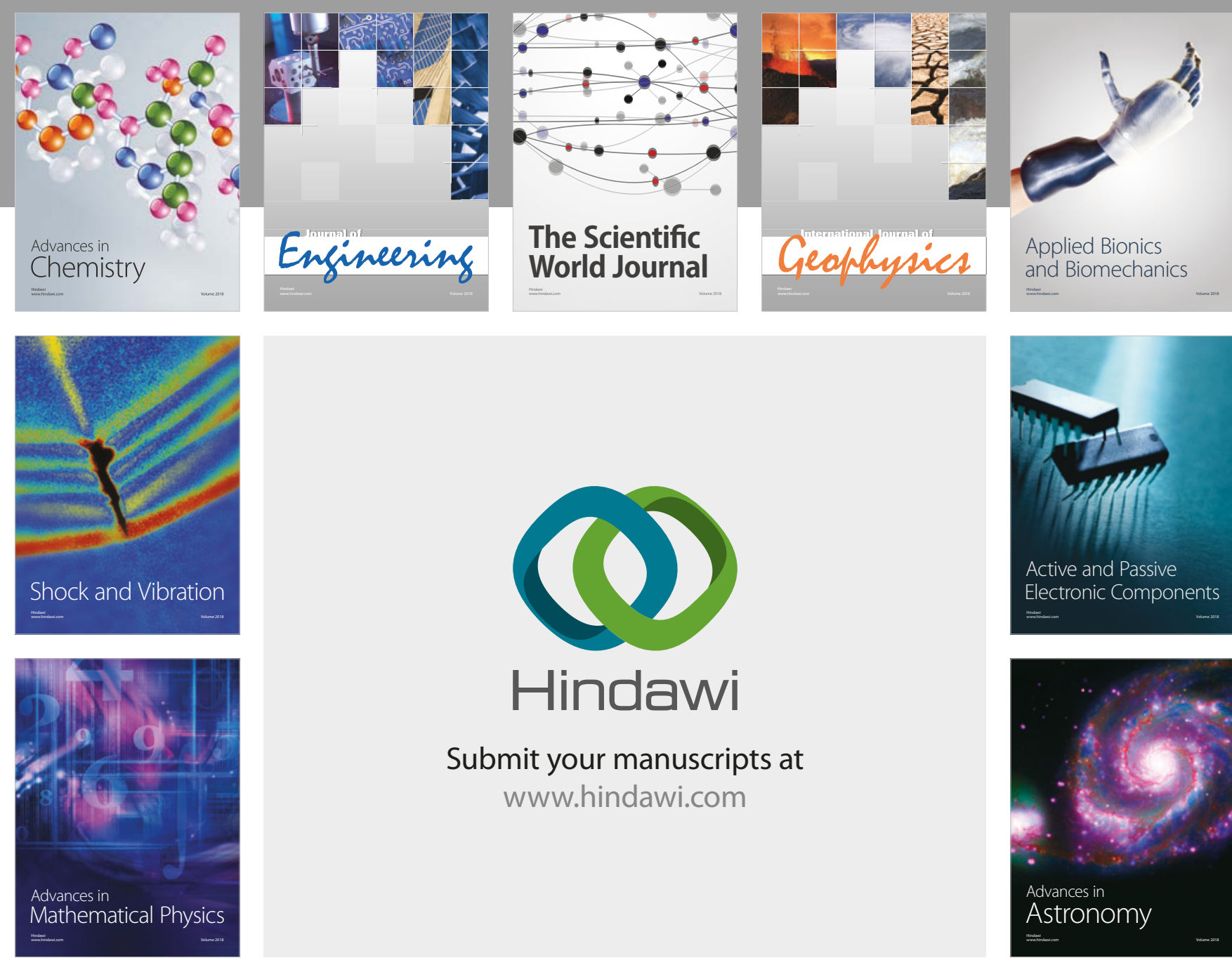

Submit your manuscripts at

www.hindawi.com

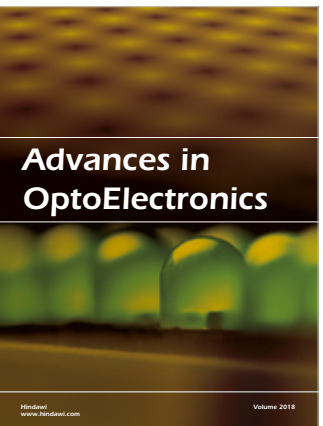

\section{Rotcting Machinery}
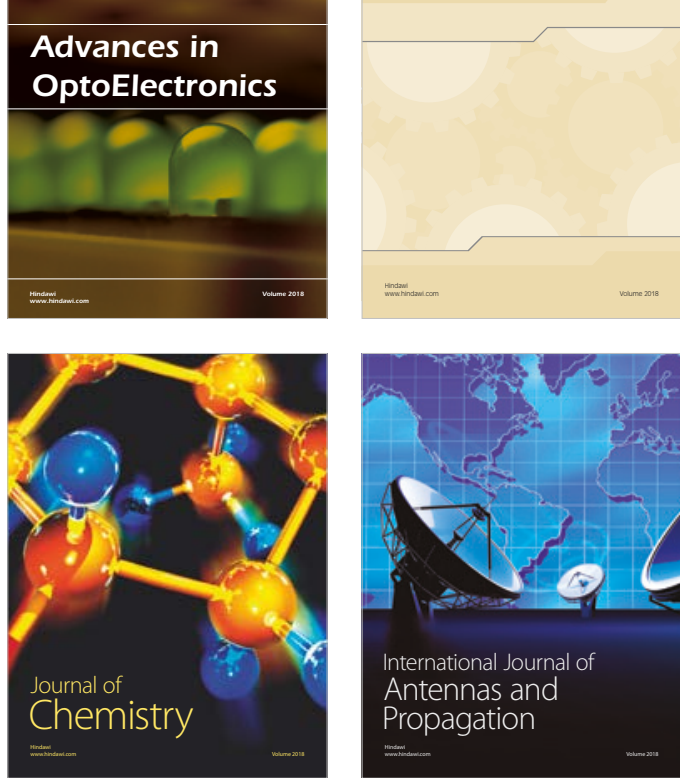

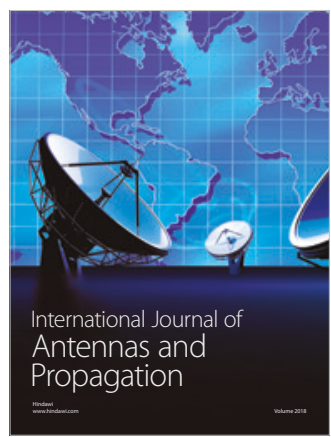

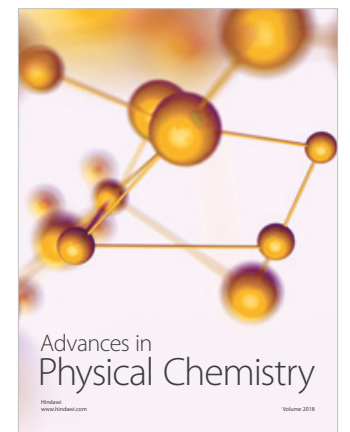

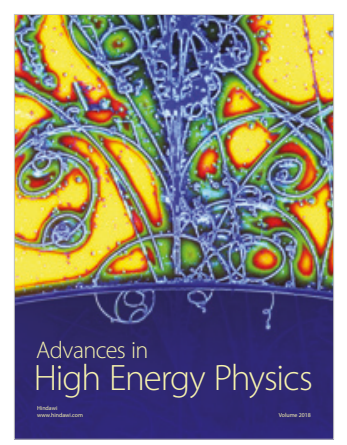

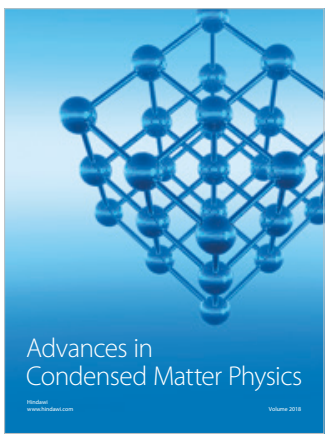

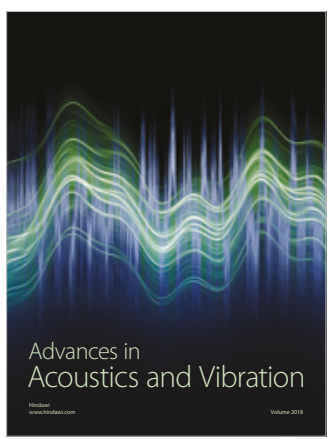

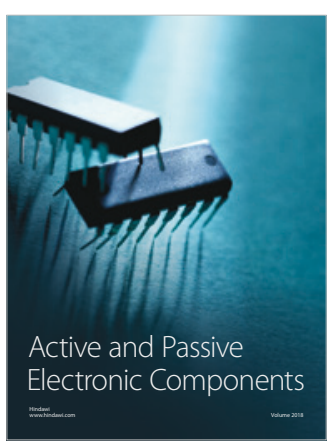
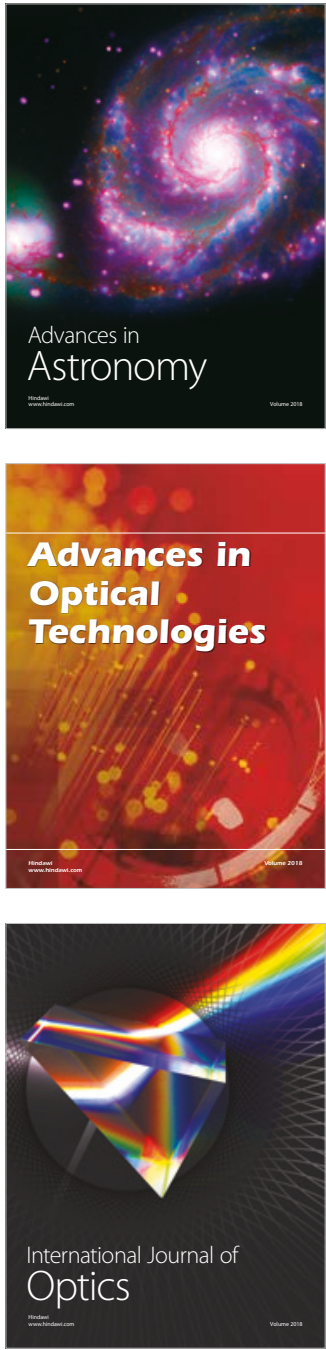